\title{
Prognostic Significance of Tissue Polypeptide- specific Antigen (TPS) in Patients With Advanced Non-small Cell Lung Cancer
}

\author{
A. van der Gaast, C.H.H. Schoenmakers, T.C. Kok, B.G. Blijenberg, \\ W.C.J. Hop and T.A.W. Splinter
}

In this study, we evaluated the prognostic value of the tumour marker, tissue polypeptide-specific antigen (TPS), in 203 patients with non-small cell lung cancer (NSCLC), and related this to several other known prognostic factors. TPS was significantly correlated with lactate dehydrogenase (LDH), $\gamma$-glutamyltranspeptidase and alkaline phosphatase, and the median level of TPS in patients with stage 4 disease was significantly higher as compared to stage $3 A$ and $3 B$ disease. In the univariate analysis, performance status, stage of disease, $\mathbf{L D H}$, alkaline phosphatase, a histology of undifferentiated large cell carcinoma and TPS all had a statistically significant association with survival. Multivariate analysis showed that stage of disease, performance status, histology and TPS were the most important prognostic factors. TPS has prognostic significance for survival in patients with advanced NSCLC, independent from performance status and stage of disease.

Key words: tissue polypeptide-specific antigen, non-small cell lung cancer, tumour markers, prognostic factors Eur F Cancer, Vol. 30A, No. 12, pp. 1783-1786, 1994

\section{INTRODUCTION}

THE TUMOUR marker, tissue polypeptide antigen (TPA), is an insoluble and heat-labile turnour-associated antigen, which was first described by Bjorklund in 1957 [1]. It has been reported that TPA is produced during the late $S$ and $G 2$ phase of the cell cycle, and is released during and immediately after mitosis [2]. By monoclonal mapping of TPA, more than 30 epitopes have been recognised [1]. The tissue polypeptide-specific antigen (TPS $^{\mathrm{TM}}$ ) ELISA is an in vitro monoclonal enzyme-linked immunosorbent assay which has been developed for the measurement of the M3-specific epitope of TPA. This epitope is thought to constitute the critical TPA specificity as related to cell proliferation. However, immunohistochemical studies also demonstrate a similarity between localisation of TPS and various cytokeratins [3].

Reports on TPA in small cell lung cancer and non-small cell lung cancer (NSCLC) have indicated that raised TPA levels are associated with a shortened survival, that TPA levels are often correlated with stage, and that serial measurements of TPA may be useful in the detection of disease recurrence [4-9]. However, such information is only scarce or not available for TPS.

The aim of the present study was to evaluate the prognostic value for survival of TPS in patients with advanced NSCLC with

Correspondence to $A$. van der Gaast.

A. van der Gaast, T.C. Kok and T.A.W. Splinter are at the Department of Medical Oncology; C.H.H. Schoenmakers and B.G. Blijenberg are at the Department of Clinical Chemistry, University Hospital RotterdamDijkzigt, Dr. Molewaterplein 40, 3015 GD Rotterdam; and W.C.J. Hop is at the Department of Epidemiology and Biostatistics, Erasmus University, Rotterdam, The Netherlands.

Revised 20 Apr. 1994, accepted 17 May 1994. regard to stage of disease, performance status, age, gender, weight loss and some biochemical parameters such as lactate dehydrogenase (LDH), $\gamma$-glutamyltranspeptidase and alkaline phosphatase.

\section{PATIENTS AND METHODS}

Patients

Serum samples were collected from 203 patients, on admittance to the Department of Medical Oncology, with histologically-proven locally-advanced (stage $3 \mathrm{~A}$ and $3 \mathrm{~B}$ ) and metastatic (stage 4) NSCLC. Serum samples of patients who presented with metastatic disease after previous local therapy (surgery or radiotherapy) were also included. The latter patients were categorised as having stage 4 disease. The samples were stored at $-70^{\circ} \mathrm{C}$ until analysis. Patients were staged according to guidelines of the American Joint Committee on Cancer [10]. Nodal status was confirmed histologically or cytologically by mediastinoscopy, mediastinotomy or thoracotomy for those patients with stage $3 \mathrm{~A}$ disease. Treatment in these patients was diverse and consisted of radiotherapy, chemotherapy or only supportive care.

\section{Marker assessment-the TPS assay}

TPS concentrations were measured with a TPS ELISA kit (BEKI Diagnostics AB, Bromma, Sweden) according to the manufacturer's instructions.

\section{Statistical methods}

Differences between the medians of two groups were tested using Mann-Whitney's test. $P=0.05$ was considered the limit of significance. To obtain approximate normal distributions, TPS, LDH, alkaline phosphatase and $\gamma$-glutamyltranspeptidase 
Table 1. Patients' characteristics

\begin{tabular}{lc}
\hline & No. of patients \\
\hline Total no. of patients & 203 \\
Sex & \\
Female & $40(20 \%)$ \\
Male & $163(80 \%)$ \\
Age (years) & 59 \\
range & $29-81$ \\
Performance status (ECOG) & \\
0 & $34(17 \%)$ \\
1 & $115(58 \%)$ \\
2 & $43(21 \%)$ \\
3 & $6(3 \%)$ \\
4 & $2(1 \%)$ \\
Stage & \\
3 A & $58(29 \%)$ \\
$3 B$ & $37(18 \%)$ \\
4 & $108(53 \%)$ \\
Histology & \\
Adenocarcinoma & $64(32 \%)$ \\
Squamous cell carcinoma & $76(37 \%)$ \\
Large cell undifferentiated carcinoma & $63(31 \%)$ \\
Treatment & \\
Chemotherapy & $186(92 \%)$ \\
No chemotherapy & $17(8 \%)$ \\
\hline
\end{tabular}

Missing data ECOG: $n=3$.

were logarithmically transformed before calculation of correlation coefficients. Survival was recorded from the date of the first TPS measurement to the date of death or last follow-up, and survival curves were calculated according to the method of Kaplan-Meier [11]. Single variable survival analysis was calculated using the logrank test [12]. Cox's regression was used to simultaneously evaluate various prognostic factors [13].

\section{RESULTS}

Patients' characteristics are listed in Table 1. 'TPS could be determined in 203 patients. At the time of the analysis, the follow-up of 186 patients was complete. 17 patients were alive with a median follow-up of 22 months. The median survival for all patients was 8 months (range $0.5-90+$ ).

The median value of TPS for all patients was $144 \mathrm{U} / \mathrm{l}$ (range 6-19208), for patients with adenocarcinoma $142 \mathrm{U} / \mathrm{l}$ (range 24-19208), for patients with squamous cell carcinoma $169 \mathrm{U} / 1$ (range 6-2284), and for patients with large cell undifferentiated carcinoma $121 \mathrm{U} / 1$ (range 36-2866). There was no significant difference between the means of TPS for the various histologies. The median values for TPS according to stage are listed in Table 2.

The percentages of patients with an arbitrarily-chosen marker

Table 2. TPS levels according to stage

\begin{tabular}{lll}
\hline TPS & Median & Range \\
\hline Stage 3A $(n=58)$ & $116^{*}$ & $6-19208$ \\
Stage 3B $(n=37)$ & $106 \dagger$ & $25-666$ \\
Stage 4 $(n=108)$ & 144 & $34-7013$ \\
\hline
\end{tabular}

Significantly different from stage $4:{ }^{*} P<0.05,+P<0.001$.

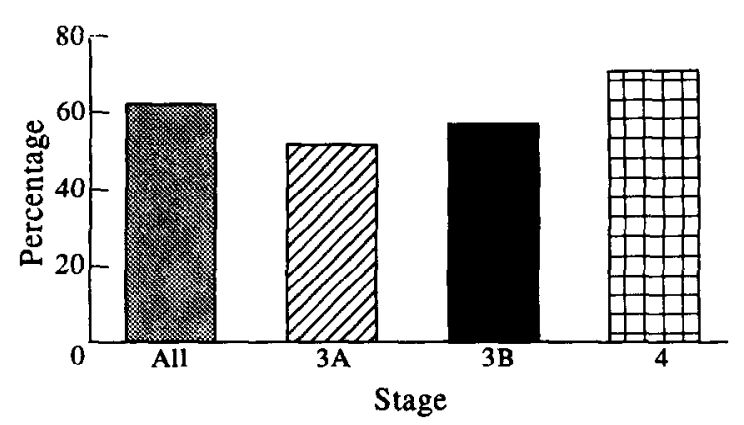

Figure 1. Percentage of patients with a TPS level $>100 \mathrm{U} / \mathrm{l}$ for all patients and according to stage.

Table 3. Correlation coefficients and significance level between lactate dehydrogenase $(\mathrm{LDH})$, alkaline phosphatase, $\gamma$-glutamyltranspeptidase ( $\gamma G T)$ and tissue polypeptide-specific antigen (TPS)

\begin{tabular}{llll} 
& LDH & $\begin{array}{c}\text { Alkaline } \\
\text { phosphatase }\end{array}$ & $\gamma \mathrm{GT}$ \\
\hline TPS & $0.50(P<0.001)$ & $0.39(P<0.001)$ & $0.37(P<0.001)$ \\
\hline
\end{tabular}

value above $100 \mathrm{U} / 1$ for all patients and according to stage are shown in Figure 1.

\section{Correlation of TPS and other biochemical parameters}

A significant correlation was found between serum TPS values and values of $\mathrm{LDH}$, alkaline phosphatase and $\gamma$-glutamyltranspeptidase. The results are shown in Table 3. An example of a scatter diagram of TPS and LDH is depicted in Figure 2.

\section{Prognostic significance of TPS}

The results of the univariate analysis are summarised in Table 4. Performance status, stage of disease, $\mathrm{LDH}$, alkaline phosphatase and TPS all had a statistically significant association with survival. Patients with a histology of undifferentiated large cell carcinoma had a significantly worse survival compared to patients with adenocarcinomas or squamous cell carcinomas. Age, weight loss, $\gamma$-glutamyltranspeptidase and gender showed no statistically significant association with survival.

Multivariate analysis (Table 5) revealed that stage of disease, performance status, histology and TPS were the most important prognostic factors. Addition of any of the other factors considered did not significantly improve the fit of the model.

The survival curves of patients based on their TPS levels are shown in Figure 3.

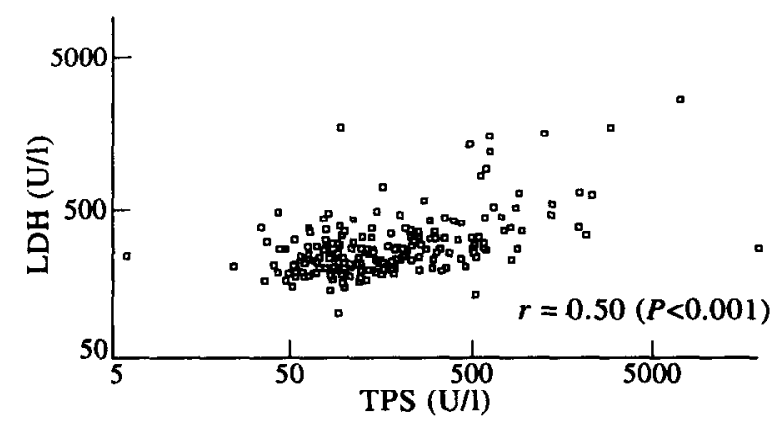

Figure 2. Scatter diagram of TPS versus LDH. 
Table 4. Single variable survival analysis

\begin{tabular}{|c|c|c|}
\hline Variable and level & $\begin{array}{l}\text { Median survival } \\
\text { (months) }\end{array}$ & $\begin{array}{c}\text { Significance level } \\
P\end{array}$ \\
\hline \multicolumn{3}{|l|}{ Stage } \\
\hline $3 A(n=58)$ & 16 & \multirow{3}{*}{$<0.001$} \\
\hline $3 \mathrm{~B}(n=37)$ & 9 & \\
\hline $4(n=108)$ & 6 & \\
\hline \multicolumn{3}{|l|}{ Histology } \\
\hline Adenocarcinoma $(n=64)$ & 10 & \multirow{3}{*}{0.04} \\
\hline Squamous cell carcinoma $(n=76)$ & 10 & \\
\hline Large cell undifferentiated $(n=63)$ & 6 & \\
\hline \multicolumn{3}{|l|}{ Sex } \\
\hline Male $(n=163)$ & 8 & \multirow{2}{*}{0.66} \\
\hline Fernale $(n=40)$ & 9 & \\
\hline \multicolumn{3}{|l|}{ Age (years) } \\
\hline$\leq 60(n=118)$ & 9 & \multirow{2}{*}{0.13} \\
\hline$>60(n=85)$ & 8 & \\
\hline \multicolumn{3}{|l|}{ Performance (WHO) } \\
\hline $0,1(n=149)$ & 10 & \multirow{2}{*}{$<0.001$} \\
\hline$\geq 2(n=51)$ & 5 & \\
\hline \multicolumn{3}{|l|}{ Weight loss } \\
\hline$<5 \mathrm{~kg}(n=146)^{*}$ & 9 & \multirow{2}{*}{0.91} \\
\hline$\geq 5 \mathrm{~kg}(n=52)$ & 8 & \\
\hline \multicolumn{3}{|l|}{ LDH (lactate dehydrogenase) } \\
\hline$\leq 300 \mathrm{U} / \mathrm{l}(n=141)$ & 10 & \multirow{2}{*}{$<0.001$} \\
\hline$>300 \mathrm{U} / 1(n=62)$ & 6 & \\
\hline \multicolumn{3}{|l|}{ Alkaline phosphatase } \\
\hline$\leq 100 \mathrm{U} / 1(n=162)$ & 10 & \multirow{2}{*}{$<0.001$} \\
\hline$>100 \mathrm{U} / \mathrm{l}(n=41)$ & 5 & \\
\hline \multicolumn{3}{|l|}{$\gamma$-glutamyltranspeptidase } \\
\hline$\leq 35 \mathrm{U} / \mathrm{l}(n=125)$ & 10 & \multirow{2}{*}{0.09} \\
\hline$>35 . \mathrm{U} / \mathrm{l}(n=78)$ & 7 & \\
\hline \multicolumn{3}{|l|}{ TPS } \\
\hline$\leq 100 \mathrm{U} / 1(n=75)$ & 11 & \multirow{2}{*}{0.002} \\
\hline$>100 \mathrm{U} / \mathrm{l}(n=128)$ & 7 & \\
\hline
\end{tabular}

*Data missing for 5 patients

Table 5. Results of Cox's multiple regression model

\begin{tabular}{llc}
\hline Variables & Relative death rate & Significance* \\
\hline Stage & & \\
3A & $1 \dagger$ & \\
3B & 1.6 & 0.03 \\
4 & 2.5 & $<0.001$ \\
Histology & & \\
Aderiocarcinoma & $1 \dagger$ & 0.34 \\
Squamous cell carcinoma & 1.2 & 0.02 \\
Large cell undifferentiated carcinoma & 1.6 & \\
Performance (WHO) & & \\
0,1 & $1 \dagger$ & $<0.001$ \\
$\geq 2$ & 2.1 & $<0.001$ \\
TPS & $1.9 \ddagger$ & \\
\hline
\end{tabular}

*For the comparison with the reference category.

$1 f$ denotes the reference category.

$\ddagger$ Effect of a 10 -fold increase of TPS (U/1). 


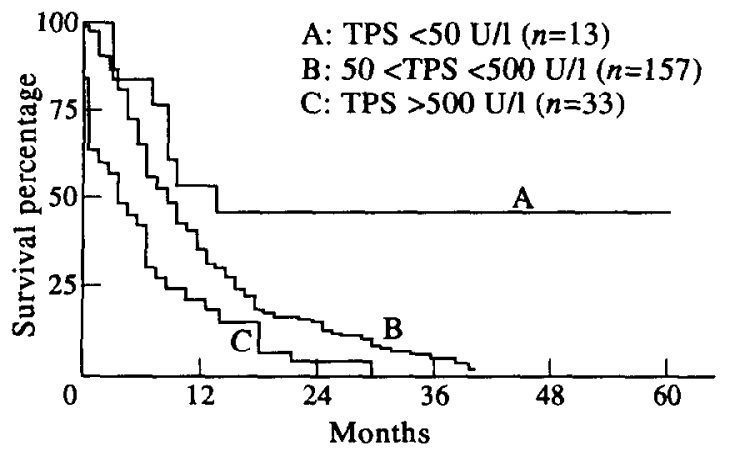

Figure 3. Survival curves of patients with NSCLC based on their TPS levels.

\section{DISCUSSION}

The prognosis of patients with inoperable NSCLC is generally poor. Only a small subset of patients may have some benefit from chemotherapy [14]. Well-established prognostic factors for survival in patients with inoperable NSCLC are stage of the disease and performance status [15]. A number of other variables, such as bone involvement, multiple metastatic site, gender, LDH, alkaline phosphatase and tumour markers, such as CEA, have also been reported to be related to prognosis. The reason that most of these variables are related to prognosis is most probably due to the fact that they give an indirect reflection of the total tumour load.

In this study, we evaluated the prognostic significance of the recently-developed tumour marker TPS, and correlated it to some other clinical and biochemical parameters. We found that $63 \%$ of 203 patients with advanced NSCLC had a serum level of TPS $>100 \mathrm{U} / 1$. No significant difference in TPS levels according to the histological type was found. The median TPS level found in patients with stage 4 disease was significantly higher as compared to stages $3 \mathrm{~A}$ and $3 \mathrm{~B}$, while the latter did not significantly differ from each other.

In the univariate analysis, TPS, stage of the disease, performance status, LDH, alkaline phosphatase and a histology of undifferentiated carcinoma compared to adenocarcinoma and squamous cell carcinoma were significant prognostic variables. However, in the multivariate analysis, only performance status, stage, histology and TPS remained as independent significant prognostic variables.

The fact that in the multivariate analysis both TPS and stage were independent prognostic factors supports the suggestion that the prognostic information obtained by TPS is additional to the total tumour load. Madersbacher and colleagues [16] have demonstrated that TPS production by prostatic epithelial cells correlated with DNA synthesis, and TPS release did not depend on cell numbers. It is possible that the additional prognostic information obtained by TPS is due to the fact that TPS is thought to be an indicator of tumour proliferation. Although we investigated the M3 monoclonal antibody (TPS), which detects the M3-specific epitope that constitutes the critical TPA speci- ficity as related to cell proliferation, the results of this study are comparable to the results of the study of Buccheri and Ferrigno [9]. They demonstrated that TPA had prognostic significance in patients with lung cancer also independent from the stage of disease.

In conclusion, TPS is an interesting tumour marker with frequently elevated levels in patients with advanced NSCLC and prognostic significance for survival, independent from performance status and stage of the disease. Further investigations are warranted to explore the potential of this marker to determine choice of treatment, and whether or not this marker can be used for disease monitoring.

1. Bjorklund B, Bjorklund V. Biochemische und morphologische grundlagen von TPA. In Luthgens $M$, Schegel $G$, eds. Tumormarkersystem CEA-TPA. Leonberg, Tumor Diagnostik Verlag, 1987, $14-30$.

2. Nathrath WBJ, Heidenkummer P, Bjorklund V, Bjorklund B. Distribution of tissue polypeptide antigen in normal human tissues: immunohistochemical study on unfixed, methanol-ethanol, and formalin-fixed tissues. 7 Histochem Cytochem 1985, 33, 99-109.

3. Liu $Q$, Nap $M$, Oehr $P$. The immunohistochemical relation between keratin, TPA and TPS in human tissues. In Klapdor R, ed. Tumor-associated Antigens, Oncogens, Receptors, Cytokines in Tumor Diagnosis and Therapy at the Beginning of the Nineties. Munchen, $W$. Zuckschwerdt Verlag GmbH, 1992, 517-521.

4. Buccheri GF, Ferrigno D, Sartoris AM, Violante B, Vola F, Curcio A. Tumor markers in bronchogenic carcinoma. Superiority of tissue polypeptide antigen to carcinoembryonic antigen and carbohydrate antigenic determinant 19-9. Cancer 1987, 60, 42-50.

5. Buccheri G, Ferrigno D. Usefulness of tissue polypeptide antigen in staging, monitoring, and prognosis of lung cancer. Chest 1988, 93, 565-570.

6. Gronowitz JS, Bergstrom R, Nou E, et al. Clinical and serologic markers of stage and prognosis in small cell lung cancer. A multivariate analysis. Cancer 1990, 66, 722-732.

7. Lee YC, Yang PC, Kuo SH, Luh KT. Tissue polypeptide antigen and carcinoembryonic antigen as tumor markers in lung cancer. Taiwan-I-Hsueh-Hui-Tsa-Chih 1991, 90, 631-636.

8. Van der Gaast A, Van Putten WL, Oosterom R, Cozijnsen M, Hoekstra R, Splinter TAW. Prognostic value of serum thymidine kinase, tissue polypeptide antigen and neuron specific enolase in patients with small cell lung cancer. BrF Cancer 1991, 64, 369-372.

9. Buccheri G, Ferrigno D. Prognostic value of the tissue polypeptide antigen in lung cancer. Chest 1992, 101, 1287-1292.

10. American Joint Committee on Cancer. Beahrs OH, Henson DE, Hutter RV, Myers MH, eds. Manual for Staging of Cancer. Philadelphia, Lippincott Co., 1988, 115-122.

11. Kaplan EL, Meier P. Nonparametric estimation from incomplete observations. F Am Stat Assoc 1958, 53, 457-481.

12. Mantel N. Evaluation of survival data and two new rank order statistics arising in its consideration. Cancer Chemother Rep 1966, 50, $163-170$.

13. Cox DR. Regression models and life tables (with discussion). $\mathcal{F}$ Roy Stat Soc B 1972, 34, 187-220.

14. Souquet PJ, Chauvin F, Boissel JP, et al. Polychemotherapy in advanced non small cell lung cancer: a meta-analysis. Lancet 1993, $342,19-21$.

15. Ruckdechsel JC, Finkelstein DM, Ettinger DS, et al. A randomized trial of the four most active regimens for metastatic non-small-cell lung cancer. $\mathcal{F}$ Clin Oncol 1986, 4, 14-22.

16. Madersbacher S, Schollhammer, Kramer G, Steiner G, Marberger M. TPS in prostatae cancer. Akt Urol 1993, 24 (suppl. 1), 36-39. 